\title{
Estimation of EuroQol 5-Dimensions health status utility values in hereditary angioedema
}

This article was published in the following Dove Press journal:

Patient Preference and Adherence

6 September 2016

Number of times this article has been viewed

\author{
Emel Aygören-Pürsün' \\ Anette Bygum ${ }^{2}$ \\ Kathleen Beusterien ${ }^{3}$ \\ Emily Hautamaki ${ }^{4}$ \\ Zlatko Sisic ${ }^{5}$ \\ Henrik B Boysen ${ }^{6}$ \\ Teresa Caballero ${ }^{7}$ \\ 'Angioedema Centre, Department \\ for Children and Adolescents, \\ University Hospital Frankfurt, \\ Goethe University, Frankfurt, \\ Germany; ${ }^{2}$ Hereditary Angioedema \\ Centre Denmark, Department of \\ Dermatology and Allergy Centre, \\ Odense University Hospital, Odense, \\ Denmark; ${ }^{3}$ Outcomes Research \\ Strategies in Health, Washington, DC, \\ ${ }^{4}$ Patient Reported Outcomes, Oxford \\ Outcomes Inc., an ICON plc company, \\ Bethesda, MD, USA; ${ }^{5}$ ViroPharma \\ Incorporated, Chatsworth House, \\ Maidenhead, UK; ${ }^{6} \mathrm{HAEi}$ - Hereditary \\ Angioedema International Patient \\ Organization for Cl Inhibitor \\ Deficiencies, Skanderborg, Denmark; \\ ${ }^{7}$ Allergy Department, Hospital La \\ Paz Institute for Health Research \\ (IdiPaz), Biomedical Research \\ Network on Rare Diseases U754 \\ (CIBERER), University Hospital La Paz, \\ Madrid, Spain
}

Correspondence: Emel Aygören-Pürsün Angioedema Centre, Department for Children and Adolescents, University Hospital Frankfurt, Goethe University, Theodor-Stern-Kai 7, 60596 Frankfurt,

Germany

Tel +496963016312

Fax+496963016491

Email aygoeren@em.uni-frankfurt.de
Objective: To estimate health status utility (preference) weights for hereditary angioedema (HAE) during an attack and between attacks using data from the Hereditary Angioedema Burden of Illness Study in Europe (HAE-BOIS-Europe) survey. Utility measures quantitatively describe the net impact of a condition on a patient's life; a score of 0.0 reflects death and 1.0 reflects full health.

Study design and methods: The HAE-BOIS-Europe was a cross-sectional survey conducted in Spain, Germany, and Denmark to assess the real-world experience of HAE from the patient perspective. Survey items that overlapped conceptually with the EuroQol 5-Dimensions (EQ-5D) domains (pain/discomfort, mobility, self-care, usual activities, and anxiety/depression) were manually crosswalked to the corresponding UK population-based EQ-5D utility weights. EQ-5D utilities were computed for each respondent in the HAE-BOIS-Europe survey for acute attacks and between attacks.

Results: Overall, a total of 111 HAE-BOIS-Europe participants completed all selected survey items and thus allowed for computation of EQ-5D-based utilities. The mean utilities for an HAE attack and between attacks were 0.44 and 0.72 , respectively. Utilities for an acute attack were dependent on the severity of pain of the last attack ( 0.61 for no pain or mild pain, 0.47 for moderate pain, and 0.08 for severe pain). There were no significant differences across countries. Mean utilities derived from the study approach compare sensibly with other disease states for both acute attacks and between attacks.

Conclusion: The impacts of HAE translate into substantial health status disutilities associated with acute attacks as well as between attacks, documenting that the detrimental effects of HAE are meaningful from the patient perspective. Results were consistent across countries with regard to pain severity and in comparison to similar disease states. The results can be used to raise awareness of HAE as a serious disease with wide-ranging personal and social impacts.

Keywords: hereditary angioedema, health-related quality of life, burden of illness, EQ-5D

\section{Introduction}

Hereditary angioedema (HAE) is a rare genetic disorder caused by $\mathrm{C} 1$ inhibitor $(\mathrm{C} 1$ $\mathrm{INH}$ ) deficiency, resulting in recurrent subcutaneous or submucosal edema. ${ }^{1-4} \mathrm{HAE}$ is a lifelong disease with symptoms often beginning in early childhood ${ }^{1,5}$ and diagnosis may be delayed for 10 years. ${ }^{3,5}$ Patients with HAE may experience disfiguring, functionally disabling, painful, and even life-threatening edema of the face, extremities, upper airway, gastrointestinal tract, and urogenital region., ${ }^{2,7}$ Attack frequency may range from rarely to once every 3 days, and the disease presentation may vary throughout a patient's life. ${ }^{2,9}$ Symptoms typically last $1-4$ days and patients may be unable to engage in normal social activities for 20-100 days per year. ${ }^{10}$ The unpredictable nature and potential seriousness of frequent angioedema attacks may put a strain on the patient and his/her 
family. Recently published data suggest that patients with HAE experience greater interference in their education and careers due to work and school absenteeism and productivity impairment during and between attacks. ${ }^{11}$ The prevalence of HAE is approximately estimated at 1:50,000. ${ }^{10,12}$

Disease management strategies include treatment of acute attacks, preprocedure attack prophylaxis, and longterm prophylaxis to minimize the frequency and severity of attacks. ${ }^{13,14}$ Treatment options mostly consist of plasmaderived or recombinant $\mathrm{C} 1 \mathrm{INH}$ concentrates and a B2 bradykinin receptor antagonist for the treatment of acute attacks. Long-term prophylaxis options involve attenuated androgens and a nanofiltered C1 INH (human). Plasma-derived C1 INHs have been recommended for preprocedure prophylaxis. ${ }^{15}$

The Hereditary Angioedema Burden of Illness Study in Europe (HAE-BOIS-Europe) survey was undertaken to collect patient-reported European data to address significant gaps in the literature with respect to the humanistic and socioeconomic burden of HAE from the patient perspective, focusing on Spain, Germany, and Denmark, as described by Bygum et a $1^{16}$ and Caballero et al. ${ }^{17}$

Despite the increasing wealth of information about the disease, the broader consequences of HAE on patients' lives are yet to be fully understood. Within this context, the objective of this study was to produce estimates of utility values associated with acute attacks as well as between attacks based on existing patient-reported data. Utility, or preference, measures allow the net impact of the effects of a condition to be captured quantitatively. ${ }^{18}$ For such measures, a score of 0.0 reflects death and a score of 1.0 reflects full health; changes of 0.05 are generally considered meaningful to the patient. ${ }^{19}$ The utility weights are often used to quality-adjust life expectancy in cost-utility evaluations of medical interventions. ${ }^{20,21}$

Given the rarity of HAE and the high cost of treatment, ${ }^{15,22}$ utility values could be an important influential factor in policy decision models and cost-utility studies of HAE treatments. Furthermore, due to the rarity and episodic nature of the condition, it may be particularly challenging to accurately estimate the clinical and humanistic impact of HAE in daily practice. Utilities can be used to raise awareness of the seriousness of HAE, provide a basis for comparison with other chronic diseases, and provide evidence of the need for more effective treatments.

\section{Patients and methods}

The HAE-BOIS-Europe survey was conducted between May and December 2011. The two study components were: 1) a one-time web- or paper-based survey on the humanistic and socioeconomic burden of HAE, which included questions regarding experience related to the last HAE attack as well as between attacks ${ }^{11,16,17}$ and 2) open-ended patient interviews $\left(\mathrm{N}=30\right.$ [n=10 per country]). ${ }^{23}$ Interview participants were selected from clinical practice centers of excellence, and survey participants were recruited systematically from clinical practice as well as from patient associations. Participants were at least 12 years of age with HAE type I or type II. The study was reviewed and approved by institutional review boards per local requirements. Interview participants provided verbal informed consent before the interview, and survey participants provided written informed consent electronically or on paper before beginning the survey. For participants under the age of 18 years, parental consent was obtained in addition to the child's assent. Means of patient recruitment, population, and attack characteristics, including use of acute attack treatment and long-term prophylaxis, have been previously published. ${ }^{11,16,17}$

An approach for obtaining utility weights for HAE attacks as well as between attacks was designed by reviewing the HAE-BOIS-Europe survey to identify items that most closely matched the EuroQol 5-Dimensions (EQ-5D) conceptually. Separate items were identified for the most recent HAE attacks and between attacks. The EQ-5D, one of the most common utility measures, is a 5-item instrument measuring current pain/discomfort, mobility, self-care, usual activities, and anxiety/depression. ${ }^{24,25}$ Each domain has three levels of severity (no problems, some or moderate problems, and extreme problems).

Response options for the selected HAE-BOIS-Europe survey items were manually crosswalked to the respective EQ-5D domain severity levels based on the judgment of four clinical expert investigators. For two items, data from the qualitative interviews also provided insight for this. Specifically, the qualitative interviews included obtaining feedback on two HAE-BOIS-Europe survey items. Patients were asked to identify a number on a $0-10$ scale reflecting their anxiety about future attacks and the impact of the last attack on their ability to perform daily activities. Patients were then asked why they chose this number. Evaluation of the results determined the ranges within the $0-10$ response scales that were assigned to the respective EQ-5D severity levels for anxiety/depression and usual activities for the acute attack. Table 1 shows the patient interpretations of the $0-10$ responses to the question inquiring about the impact of the last attack on usual activities, and Table 2 shows the patient interpretations of the $0-10$ responses to the item inquiring about anxiety about having an attack in the future. Based 


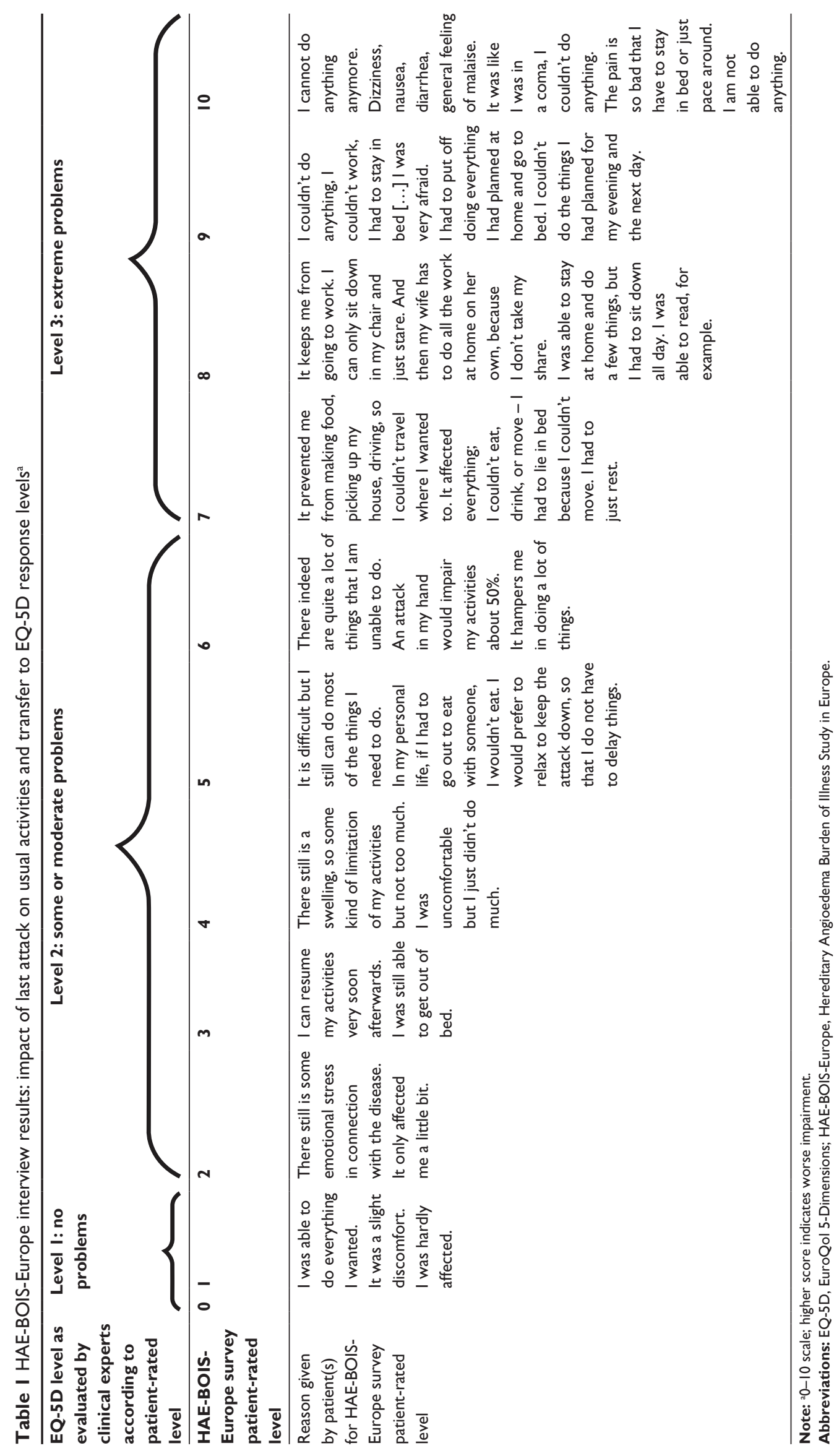




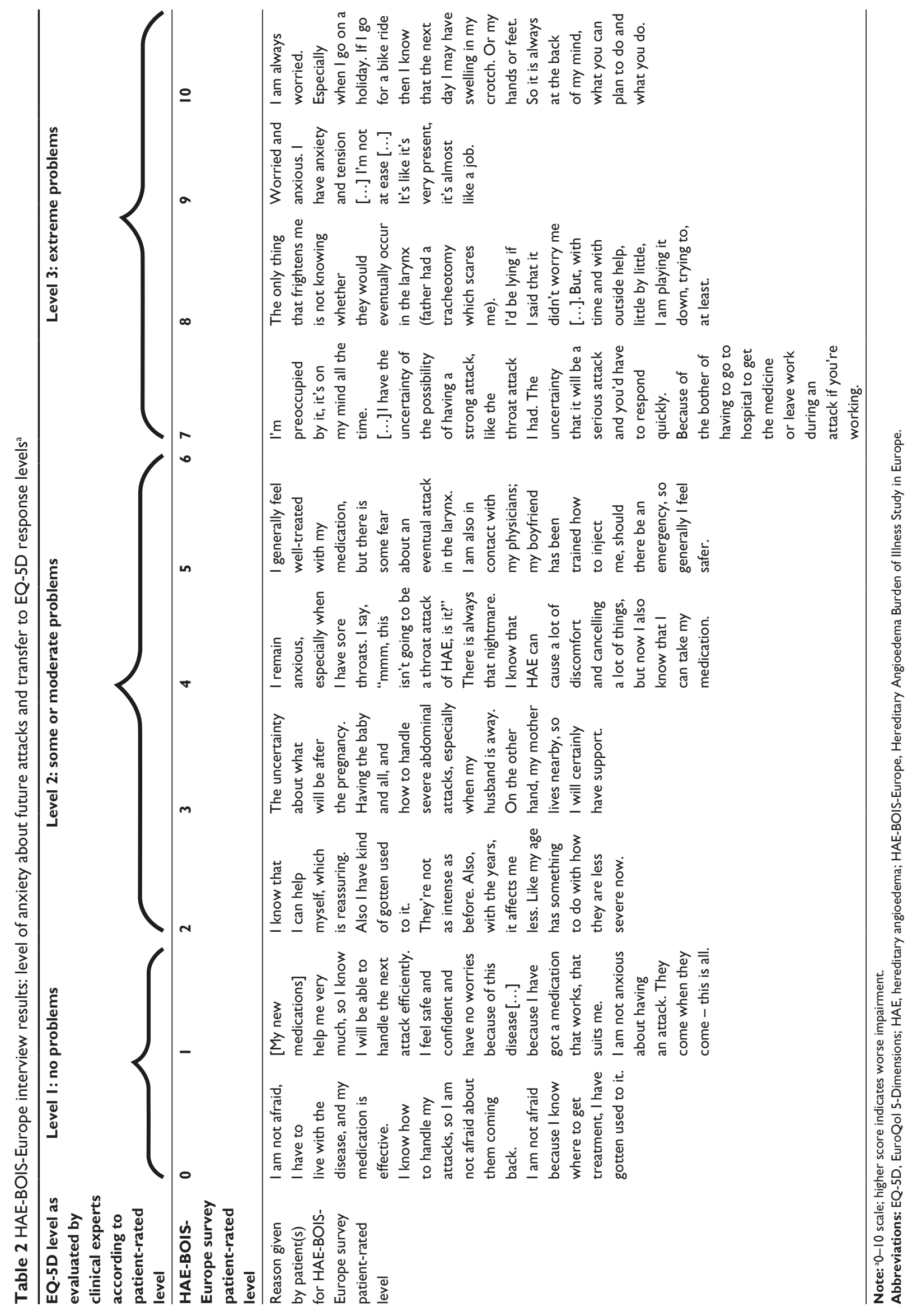


on the interpretations, it was determined that for both usual activities and anxiety/depression, the numerical responses 0-1 would be best assigned to the EQ-5D severity level no problems, 2-6 to some or moderate problems, and 7-10 to extreme problems. With respect to the EQ-5D self-care and mobility domains, it was assumed that self-care is not impacted during an attack or between attacks and that mobility is not impacted between attacks; this is a conservative approach and an acknowledged potential limitation. Only patients who had had an attack within the past 6 months were included in the analysis.

Each of the EQ-5D levels has a predetermined utility weight based on the time trade-off exercise; the present research used UK general population weights, as detailed by Dolan. ${ }^{19}$ Table 3 shows, for both an attack and between attacks, how each EQ-5D domain severity level and respective UK population disutility weight were linked to the respective HAE-BOIS-Europe survey items and responses. These negative values were added to 1.0 to arrive at an overall EQ-5D index score. ${ }^{26}$ The formula was applied to the respondents of the HAE-BOIS-Europe survey on the individual patient level. Mean EQ-5D utility scores were calculated for the last attack, overall, and by pain severity (no/mild, moderate, and severe pain), as well as for between attacks. Country-specific utility scores were also computed. As shown in Table 3, to assess pain and discomfort during the latest HAE attack from the HAE-BOIS survey, patients answered the question "what was the worst pain you had during your most recent HAE attack?" Possible responses were "no pain", "mild or moderate pain", or "severe pain", which very closely matches "no pain or discomfort", "moderate pain or discomfort", and "extreme pain or discomfort" on the EQ-5D pain/discomfort domain, and so mapping here involved a direct translation of responses. Between attacks, this was interpreted from the HAE-BOIS survey question, "In general, how would you describe your health?" with the answer of "excellent or very good" being translated as "no pain or discomfort" on the EQ-5D pain and discomfort domain, "good and fair" to indicate "moderate pain or discomfort", and "poor" to be indicative of "extreme pain or discomfort". An analysis of variance test was used to compare differences in utility scores across countries as well as across pain severity levels of the last attack. SAS ${ }^{\circledR}$ Enterprise Guide ${ }^{\circledR} 4.3$ (SAS Institute Inc., Cary, NC, USA) was used for all analyses.

\section{Results}

Overall, a total of 111 HAE-BOIS-Europe survey participants completed all of the selected items (41 Spain, 40 Germany,
30 Denmark; 51\% female; average [range] age: 40 [16-81] years). The mean EQ-5D utility scores for the last HAE attack and for between attacks were 0.444 and 0.722 , respectively and comparable across countries. Utilities worsened as attack pain increased $($ no $/$ mild pain $=0.613$; moderate pain $=0.467$; and severe pain $=0.080 ; P<0.001$; Table 4$)$. For both acute attacks and between attacks, the domains with the greatest percentages indicating impairment were pain/discomfort and anxiety/depression. For pain/discomfort, $90 \%$ and $81 \%$ of patients indicated at least some impairment for acute attacks and between attacks, respectively; for anxiety/depression, $76 \%$ and $49 \%$ indicated at least some impairment for acute attacks and between attacks, respectively. Results were consistent across countries.

\section{Discussion}

This research presents an approach for estimating EQ-5D utility values during an HAE attack as well as between attacks. This approach is sensible based on the reasonable overlap of concepts between the respective HAE-BOIS-Europe survey items and the EQ-5D. The findings suggest that both during and between attacks, HAE causes substantial suffering from the patient perspective. This research fills an unmet need in the HAE literature, providing preference estimates in HAE, based on patient-reported impacts that could be used in future cost-utility analyses of HAE therapies.

In HAE, utility values have previously been measured in the following ways: clinician report reflecting the clinician's perception of the patient's experience of a moderate or severe attack; $;{ }^{27}$ using the standard gamble approach for HAE health states in a general population sample (comparing the health states of HAE without any effective emergency medication, HAE with effective emergency medication available in a hospital, and HAE with effective emergency medication available for self-administration); ${ }^{28}$ and retrospectively in a survey in which HAE patients estimated EQ-5D responses for the attack-free and acute attack states but did not include disease-specific considerations. ${ }^{29}$ This study has taken a different approach by estimating utilities based on HAE disease-specific items characterizing the patient's reported disease experience.

Our results show that patients with HAE experience low utilities during acute attacks, and this is dependent upon the pain severity of the attack. Indeed, we observed statistically significant differences between the utility values of different attack severities, suggesting that utilities could discriminate between mild/moderate and severe attacks. The utility for a severe attack was very low, 0.08, indicating substantial 
Table 3 Mapping of EQ-5D responses to HAE-BOIS-Europe survey items

\begin{tabular}{|c|c|c|c|c|c|}
\hline \multirow{2}{*}{$\begin{array}{l}\text { EQ-5D } \\
\text { domain }^{26}\end{array}$} & \multirow[t]{2}{*}{ EQ-5D description ${ }^{26}$} & \multirow{2}{*}{$\begin{array}{l}\text { EQ-5D } \\
\text { disutility } \\
(\text { UK) }\end{array}$} & & \multicolumn{2}{|c|}{ Rating of HAE-BOIS-Europe survey items for EQ-5D utility } \\
\hline & & & & During the latest attack & Between attacks \\
\hline \multicolumn{2}{|c|}{ Pain/discomfort } & & $\begin{array}{l}\text { Question } \\
\text { on survey }\end{array}$ & $\begin{array}{l}\text { What was the worst pain you had } \\
\text { during your most recent HAE attack? }\end{array}$ & $\begin{array}{l}\text { In general, how would you } \\
\text { describe your health? }\end{array}$ \\
\hline Level I & No pain or discomfort & -0.0 & & No pain & Excellent or very good \\
\hline Level 2 & Moderate pain or discomfort & -0.123 & & Mild or moderate pain & Good or fair \\
\hline Level 3 & Extreme pain or discomfort & -0.386 & & Severe pain & Poor \\
\hline Mobility & & & $\begin{array}{l}\text { Question } \\
\text { on survey }\end{array}$ & $\begin{array}{l}\text { How long did the attack stop you } \\
\text { from performing daily activities? }\end{array}$ & $\mathrm{N} / \mathrm{A}$ \\
\hline Level I & $\begin{array}{l}\text { No problems in walking } \\
\text { about }\end{array}$ & -0.0 & & $2 \mathrm{~h}$ or $2-4 \mathrm{~h}$ & $\begin{array}{l}\text { Assume HAE does not impact } \\
\text { mobility between attacks } \\
\text { (ie, EQ-5D disutility }=-0.0 \text { ) }\end{array}$ \\
\hline Level 2 & $\begin{array}{l}\text { Some problems in walking } \\
\text { about }\end{array}$ & -0.069 & & $4-12 \mathrm{~h}, 12-24 \mathrm{~h}$, or $2 \mathrm{~d}$ & \\
\hline Level 3 & Confined to bed & -0.314 & & $3 \mathrm{~d}, 4 \mathrm{~d}$, or $>4 \mathrm{~d}$ & \\
\hline Self-care & & & $\begin{array}{l}\text { Question } \\
\text { on survey }\end{array}$ & $\mathrm{N} / \mathrm{A}$ & $\mathrm{N} / \mathrm{A}$ \\
\hline Level I & No problems with self-care & -0.0 & & $\begin{array}{l}\text { Assume HAE attack does not } \\
\text { impact self-care (ie, EQ-5D } \\
\text { disutility }=-0.0 \text { ) }\end{array}$ & $\begin{array}{l}\text { Assume HAE does not impact self- } \\
\text { care between attacks (ie, EQ-5D } \\
\text { disutility }=-0.0 \text { ) }\end{array}$ \\
\hline Level 2 & $\begin{array}{l}\text { Some problems washing or } \\
\text { dressing myself }\end{array}$ & -0.104 & & & \\
\hline Level 3 & $\begin{array}{l}\text { Unable to wash or dress } \\
\text { myself }\end{array}$ & -0.214 & & & \\
\hline \multicolumn{2}{|c|}{ Usual activities } & & $\begin{array}{l}\text { Question } \\
\text { on survey }\end{array}$ & $\begin{array}{l}\text { During your most recent attack, } \\
\text { how much did the HAE attack } \\
\text { affect your ability to do your } \\
\text { regular daily activities, other than } \\
\text { work at a job/be a student? }\end{array}$ & $\begin{array}{l}\text { In the past } 6 \text { months, please think } \\
\text { how much HAE affected your } \\
\text { ability to do your regular daily } \\
\text { activities, other than work at a } \\
\text { job/be a student, between attacks }\end{array}$ \\
\hline Level I & $\begin{array}{l}\text { No problems with } \\
\text { performing my usual activities }\end{array}$ & -0.0 & & $\begin{array}{l}\text { No problems (ie, HAE-BOIS- } \\
\text { Europe survey patient-rated } \\
\text { level }=0.0-1.0 \text { ) }\end{array}$ & $\begin{array}{l}\text { No problems (ie, HAE-BOIS- } \\
\text { Europe survey patient-rated } \\
\text { level }=0.0-1.0 \text { ) }\end{array}$ \\
\hline Level 2 & $\begin{array}{l}\text { Some problems with } \\
\text { performing my usual activities }\end{array}$ & -0.036 & & $\begin{array}{l}\text { Some or moderate levels } \\
\text { (ie, HAE-BOIS-Europe survey } \\
\text { patient-rated level =2.0-6.0) }\end{array}$ & $\begin{array}{l}\text { Some or moderate levels } \\
\text { (ie, HAE-BOIS-Europe survey } \\
\text { patient-rated level =2.0-6.0) }\end{array}$ \\
\hline Level 3 & $\begin{array}{l}\text { Unable to perform my usual } \\
\text { activities }\end{array}$ & -0.094 & & $\begin{array}{l}\text { Extreme problems } \\
\text { (ie, HAE-BOIS-Europe survey } \\
\text { patient-rated level =7.0-10.0) }\end{array}$ & $\begin{array}{l}\text { Extreme problems } \\
\text { (ie, HAE-BOIS-Europe survey } \\
\text { patient-rated level =7.0-10.0) }\end{array}$ \\
\hline \multicolumn{2}{|c|}{ Anxiety/depression } & & $\begin{array}{l}\text { Question } \\
\text { on survey }\end{array}$ & $\begin{array}{l}\text { How anxious are you about having } \\
\text { an HAE attack in the future? }\end{array}$ & $\begin{array}{l}\text { Average of How often did you } \\
\text { get sudden feelings of panic about } \\
\text { HAE symptoms/attacks during } \\
\text { the past } 6 \text { months? and How } \\
\text { distressed are you about your } \\
\text { HAE attacks/symptoms now? } \\
\text { (I-5 scale each) }\end{array}$ \\
\hline Level I & Not anxious or depressed & -0.0 & & $\begin{array}{l}\text { No problems (ie, HAE-BOIS- } \\
\text { Europe survey patient-rated } \\
\text { level }=0.0-1.0 \text { ) }\end{array}$ & $\begin{array}{l}\text { HAE-BOIS-Europe survey patient- } \\
\text { rated level }<2.5 \text { ( } \mathrm{I}-5 \text { scale) }\end{array}$ \\
\hline Level 2 & $\begin{array}{l}\text { Moderately anxious or } \\
\text { depressed }\end{array}$ & $-0.07 \mid$ & & $\begin{array}{l}\text { Some or moderate levels } \\
\text { (ie, HAE-BOIS-Europe survey } \\
\text { patient-rated level =2.0-6.0) }\end{array}$ & $\begin{array}{l}\text { HAE-BOIS-Europe survey patient- } \\
\text { rated level }=2.5-4.0\end{array}$ \\
\hline Level 3 & $\begin{array}{l}\text { Extremely anxious or } \\
\text { depressed }\end{array}$ & -0.236 & & $\begin{array}{l}\text { Extreme problems } \\
\text { (ie, HAE-BOIS-Europe survey } \\
\text { patient-rated level =7.0-10.0) }\end{array}$ & $\begin{array}{l}\text { HAE-BOIS-Europe survey patient- } \\
\text { rated level }>4.0 \text { ( } 1-5 \text { scale })\end{array}$ \\
\hline
\end{tabular}

Notes: For EQ-5D disutility (UK), the constant term accounted for any dysfunctional state $=-0.08$, the constant term N3 accounted for if level 3 occurs within at least one dimension: -0.269 , and full health $=1$. The summation of EQ-5D disutility (UK) values, including these three terms and EQ-5D disutility values for each EQ-5D domain at one of three levels in each domain, gives rise to the estimated value of EQ-5D utility. ${ }^{26}$

Abbreviations: EQ-5D, EuroQol 5-Dimensions; HAE, hereditary angioedema; HAE-BOIS-Europe, Hereditary Angioedema Burden of Illness Study in Europe; h, hours, d, days; N/A, not applicable. 
Table 4 Estimated EQ-5D utilities during and between attacks by country

\begin{tabular}{|c|c|c|c|c|c|c|c|c|c|}
\hline \multirow{2}{*}{$\begin{array}{l}\text { HAE-related } \\
\text { health state }\end{array}$} & \multicolumn{2}{|l|}{ All } & \multicolumn{2}{|c|}{ Spain } & \multicolumn{2}{|c|}{ Germany } & \multicolumn{2}{|c|}{ Denmark } & \multirow[t]{2}{*}{$P$-value ${ }^{a}$} \\
\hline & $\mathbf{n}$ & Mean \pm SD & $\mathbf{n}$ & Mean \pm SD & $\mathbf{n}$ & Mean \pm SD & $\mathbf{n}$ & Mean \pm SD & \\
\hline \multicolumn{10}{|l|}{ Acute HAE state } \\
\hline Overall & 111 & $0.444 \pm 0.30$ & 41 & $0.412 \pm 0.30$ & 40 & $0.5 \mid 4 \pm 0.29$ & 30 & $0.396 \pm 0.32$ & 0.184 \\
\hline \multicolumn{10}{|c|}{ By pain severity of last attack:* } \\
\hline No pain or mild & 41 & $0.613 \pm 0.26$ & 22 & $0.538 \pm 0.28$ & 12 & $0.672 \pm 0.22$ & 7 & $0.745 \pm 0.22$ & \\
\hline Moderate & 48 & $0.467 \pm 0.27$ & 14 & $0.358 \pm 0.25$ & 19 & $0.606 \pm 0.20$ & 15 & $0.394 \pm 0.27$ & \\
\hline Severe & 22 & $0.080 \pm 0.08$ & 5 & $0.006 \pm 0.01$ & 9 & $0.110 \pm 0.08$ & 8 & $0.093 \pm 0.09$ & \\
\hline Between HAE attacks & III & $0.722 \pm 0.23$ & 41 & $0.705 \pm 0.26$ & 40 & $0.737 \pm 0.19$ & 30 & $0.728 \pm 0.24$ & 0.816 \\
\hline
\end{tabular}

Notes: aAnalysis of variance test. ${ }^{*} P<0.001$ for comparison of differences in utility values by pain severity levels among overall sample.

Abbreviations: EQ-5D, EuroQol 5-Dimensions; HAE, hereditary angioedema; SD, standard deviation.

patient burden. In addition, between attacks, utilities do not reach UK general population norms ( 0.72 compared with $0.86 ; P<0.001) .{ }^{30}$ In contrast, utilities for the chronic state appear to be similar to UK population norms for other episodic diseases (migraine, epilepsy), suggesting that HAE as a condition has further long-term impacts on patients' lives even when they are not having an attack. ${ }^{31,32}$

In comparison with the published literature reporting utilities for other disease areas, between attacks the mean utility is similar (ie, $<0.05$ difference) to that of partially controlled or uncontrolled asthma $(0.72)^{33}$ and ankylosing spondylitis $(0.69$; Table 5). ${ }^{34}$ The mean utility of an acute HAE attack (0.44) is comparable to that of ischemic heart disease with moderate/ severe angina $(0.45)^{35}$ or renal failure on hemodialysis $(0.44){ }^{36}$ Furthermore, an EQ-5D value of 0.44 indicates that the general population would be willing to trade off $56 \%$ of their remaining life to avoid living in that health state.
Study limitations include the use of an indirect nonvalidated approach for obtaining EQ-5D-based utilities. Nevertheless, the use of mapping to predict utility values has been broadly used previously ${ }^{37}$ and the HAE-BOIS-Europe survey items selected for the manual crosswalking to the EQ-5D appear to be sufficiently comparable conceptually. A comparison with utilities derived from the EQ-5D instrument would be a useful area for future study. In addition, it was assumed that attacks do not impact self-care and that between attacks, there is no impact on self-care or mobility; while the results appear sensible and compare realistically to other disease states, this approach may underestimate patient burden. Nonetheless, utilities were derived based on patient-reported responses to disease-specific items; this should result in more disease-specific results. Also, the results are consistent on several levels: overall mean utilities derived from the study approach compare sensibly

Table 5 EQ-5D utilities reported for selected conditions

\begin{tabular}{|c|c|c|}
\hline Reference/country & Condition & Utility \\
\hline Stafford et al (20I2)/UK ${ }^{31}$ & Migraine: chronic state & 0.87 \\
\hline Kind et al (1999)/UK ${ }^{30}$ & UK general population norm & 0.86 \\
\hline Westerhuis et al $(201 \mathrm{I}) /$ the Netherlands $^{32}$ & Epilepsy & 0.80 \\
\hline Dyer et al $(2010) /$ worldwide ${ }^{35}$ & Ischemic heart disease with mild angina & 0.80 \\
\hline Ismail et al (2010)/England ${ }^{38}$ & Type I diabetes mellitus & 0.79 \\
\hline Terzano et al $(2012) / /$ taly $y^{33}$ & Asthma, partially controlled or uncontrolled & 0.72 \\
\hline HAE-BOIS-Europe ${ }^{\mathrm{a}}$ & HAE: chronic (between attacks) & 0.72 \\
\hline Mustur et al (2009)/Montenegro ${ }^{34}$ & Ankylosing spondylitis & 0.69 \\
\hline Marra et al (2004)/Canada ${ }^{39}$ & Rheumatoid arthritis & 0.66 \\
\hline Pickard et al (2004)/Canada ${ }^{40}$ & 6 months after stroke & 0.62 \\
\hline HAE-BOIS-Europe ${ }^{a}$ & HAE: attack with no pain or mild pain & 0.61 \\
\hline Stafford et al (20I2)/UK ${ }^{31}$ & Migraine: moderate severity & 0.53 \\
\hline HAE-BOIS-Europe & HAE: attack with moderate pain & 0.47 \\
\hline Dyer et al $(2010) /$ worldwide ${ }^{35}$ & Ischemic heart disease with moderate/severe angina & 0.45 \\
\hline Lee et al (2005)/Wales ${ }^{36}$ & Renal failure on hemodialysis & 0.44 \\
\hline HAE-BOIS-Europe ${ }^{a}$ & HAE: acute attack (overall) & 0.44 \\
\hline Pickard et al (2004)/Canada ${ }^{40}$ & Acute stroke & 0.31 \\
\hline HAE-BOIS-Europe ${ }^{\mathrm{a}}$ & HAE: attack with severe pain & 0.08 \\
\hline
\end{tabular}

Note: aRefers to current study with data shown in bold.

Abbreviations: EQ-5D, EuroQol 5-Dimensions; HAE, hereditary angioedema; HAE-BOIS-Europe, Hereditary Angioedema Burden of Illness Study in Europe. 
with other disease states for both acute attacks and between attacks (Table 5). As expected, as pain severity increased, attack utilities declined and were comparable with conditions generally considered more severe; these values were consistent across countries. Future research might incorporate this methodology, providing additional data that may substantiate the validity of our approach.

\section{Conclusion}

In summary, acute attacks as well as the chronic experience of HAE impair patients' quality of life to a degree similar to that of other serious chronic diseases. This suggests that the detrimental effects of HAE as a lifelong disease characterized by acute attacks are meaningful and may cause long-lasting lifestyle impairment. This may translate into long-term reductions in quality of life. Our findings suggest that despite the availability of various treatment options, more comprehensive disease management strategies need to be considered to minimize the severity, frequency, and overall impact of HAE attacks. Utility values can be used to help advocate for and raise awareness among policymakers, the global community, and the clinical community of the burden of HAE and the substantial unmet need for effective treatments.

\section{Acknowledgments}

The authors thank the following organizations for their assistance with HAE patient recruitment for this study: Hudafdeling I og Allergicentret, Odense Universitetshospital, Denmark; Klinik für Kinder - und Jugendmedizin, Universitätsklinikum Frankfurt, Goethe-Universität Frankfurt, Germany; Servicio de Alergia, Hospital Universitario La Paz, Spain; HAEiInternational Patient Organization for C1 Inhibitor Deficiencies; the Danish HAE Patient Association (patientforeningen HAE danmark); the German HAE Patient Association (HAE Vereinigung e.V.); and the Spanish Association for Hereditary Angioedema (AEDAF).

This study was sponsored by ViroPharma SPRL-BVBA (now part of the Shire Group of Companies). Editorial assistance was provided by Linda Wagner, PharmD; David Lickorish, PhD; and Sally Hassan, PhD of Excel Scientific Solutions, and funded by Shire.

\section{Author contributions}

EAP, AB, and TC contributed to the study design, participated in the acquisition and analysis of patient data, and provided substantive input to the manuscript. $\mathrm{KB}$ and $\mathrm{EH}$ contributed to the study design and provided input on survey design, analysis, and medical writing support on behalf of the HAE-BOIS-Europe Steering Committee. ZS coordinated the work of the Steering Committee, performed literature searches, and provided substantive input to the manuscript. HBB contributed to the study design, participated in the acquisition of patient data, and provided substantive input to the manuscript. All authors contributed to the study design, acquisition of data, analysis, or interpretation of data, and contributed to drafting or revising the manuscript. All authors read and approved the final manuscript and agree to be accountable for the data reported herein.

\section{Disclosure}

EAP has received sponsorship for educational purposes and has provided consultancy services or has participated in clinical trials sponsored by CSL Behring, Jerini AG/Shire, Sobi, ViroPharma Incorporated (now part of the Shire Group of Companies), and Biocryst. AB has been involved in clinical research or educational events involving CSL Behring, Jerini AG/Shire, Sobi, and ViroPharma Incorporated. At the time of the study $\mathrm{KB}$ and $\mathrm{EH}$ were employees of Oxford Outcomes Inc., an ICON plc company, which consults for ViroPharma Incorporated. ZS was an employee of ViroPharma Incorporated at the time of this study. HBB is the Executive Director of HAEi-International Patient Organization for C1 Inhibitor Deficiencies, which receives funding from most pharmaceutical companies, including ViroPharma Incorporated. TC has received sponsorship for educational purposes, has been paid for providing consultancy services, or has participated in clinical trials sponsored by CSL Behring, Jerini AG/Shire, Pharming NV, Sobi, and ViroPharma Incorporated. The authors report no other conflicts of interest in this work.

\section{References}

1. Agostoni A, Aygören-Pürsün E, Binkley KE, et al. Hereditary and acquired angioedema: problems and progress: proceedings of the third C1 esterase inhibitor deficiency workshop and beyond. J Allergy Clin Immunol. 2004;114(3 Suppl):S51-S131.

2. Bork K, Meng G, Staubach P, Hardt J. Hereditary angioedema: new findings concerning symptoms, affected organs, and course. Am J Med. 2006; 119(3):267-274.

3. Bygum A. Hereditary angio-oedema in Denmark: a nationwide survey. Br J Dermatol. 2009;161(5):1153-1158.

4. Caballero T, Baeza ML, Cabanas R, et al; Spanish Study Group on Bradykinin-Induced Angioedema; Grupo Español de Estudio del Angioedema mediado por Bradicinina. Consensus statement on the diagnosis, management, and treatment of angioedema mediated by bradykinin. Part I. Classification, epidemiology, pathophysiology, genetics, clinical symptoms, and diagnosis. J Investig Allergol Clin Immunol. 2011;21(5):333-347; quiz follow 347.

5. Roche O, Blanch A, Caballero T, Sastre N, Callejo D, Lopez-Trascasa M. Hereditary angioedema due to $\mathrm{C} 1$ inhibitor deficiency: patient registry and approach to the prevalence in Spain. Ann Allergy Asthma Immunol. 2005;94(4):498-503. 
6. Frank MM, Gelfand JA, Atkinson JP. Hereditary angioedema: the clinical syndrome and its management. Ann Intern Med. 1976;84(5):580-593.

7. Bork K, Hardt J, Schicketanz KH, Ressel N. Clinical studies of sudden upper airway obstruction in patients with hereditary angioedema due to $\mathrm{C} 1$ esterase inhibitor deficiency. Arch Intern Med. 2003;163(10):1229-1235.

8. Bork K, Hardt J, Witzke G. Fatal laryngeal attacks and mortality in hereditary angioedema due to C1-INH deficiency. J Allergy Clin Immunol. 2012;130(3):692-697.

9. Gower RG, Lumry WR, Davis-Lorton MA, Johnston DT, Busse PJ. Current options for prophylactic treatment of hereditary angioedema in the United States: patient-based considerations. Allergy Asthma Proc. 2012;33(3):235-240.

10. Cicardi M, Agostoni A. Hereditary angioedema. N Engl J Med. 1996; 334(25):1666-1667.

11. Aygören-Pürsün E, Bygum A, Beusterien K, et al. Socioeconomic burden of hereditary angioedema: results from the hereditary angioedema burden of illness study in Europe. Orphanet J Rare Dis. 2014;9:99.

12. Zuraw BL. Clinical practice. Hereditary angioedema. $N$ Engl J Med. 2008;359(10):1027-1036.

13. Bowen T, Cicardi M, Farkas H, et al. 2010 International consensus algorithm for the diagnosis, therapy and management of hereditary angioedema. Allergy Asthma Clin Immunol. 2010;6(1):24.

14. Cicardi M, Bork K, Caballero T, et al; HAWK (Hereditary Angioedema International Working Group). Evidence-based recommendations for the therapeutic management of angioedema owing to hereditary $\mathrm{C} 1$ inhibitor deficiency: consensus report of an International Working Group. Allergy. 2012;67(2):147-157.

15. Craig T, Aygören-Pürsün E, Bork K, et al. WAO guideline for the management of hereditary angioedema. World Allergy Organ J. 2012;5(12): 182-199.

16. Bygum A, Aygören-Pürsün E, Caballero T, et al. The hereditary angioedema burden of illness study in Europe (HAE-BOIS-Europe): background and methodology. BMC Dermatol. 2012;12:4.

17. Caballero T, Aygören-Pürsün E, Bygum A, et al. The humanistic burden of hereditary angioedema: results from the Burden of Illness Study in Europe. Allergy Asthma Proc. 2014;35(1):47-53.

18. Tolley K. What Are Health Utilities? 2nd ed. London: Hayward Medical Communications; 2009.

19. Dolan P. Modeling valuations for EuroQol health states. Med Care 1997;35(11):1095-1108.

20. Drummond MF, Iglesias CP, Cooper NJ. Systematic reviews and economic evaluations conducted for the National Institute for Health and Clinical Excellence in the United Kingdom: a game of two halves? Int $J$ Technol Assess Health Care. 2008;24(2):146-150.

21. Phillips C. What Is a QALY? 2nd ed. London: Hayward Medical Communications; 2009.

22. Wilson DA, Bork K, Shea EP, Rentz AM, Blaustein MB, Pullman WE. Economic costs associated with acute attacks and long-term management of hereditary angioedema. Ann Allergy Asthma Immunol. 2010; 104(4):314-320.

23. Bygum A, Aygören-Pürsün E, Beusterien K, et al. Burden of illness in hereditary angioedema: a conceptual model. Acta Derm Venereol. 2015; 95(6):706-710.

24. EuroQol Group. What Is EQ-5D; 2013. Available from: http://www. euroqol.org/about-eq-5d.html. Accessed September 19, 2014.

25. Sullivan PW, Slejko JF, Sculpher MJ, Ghushchyan V. Catalogue of EQ-5D scores for the United Kingdom. Med Decis Making. 2011;31(6):800-804
26. Dolan P, Gudex C, Kind P, Williams A. A social tariff for EuroQol: Results from a UK general population survey. The University of York Centre for Health Economics 1995, Discussion Paper 138; 1995. Available from: http://www.york.ac.uk/che/pdf/DP138.pdf. Accessed May 10, 2016.

27. Helbert M, Pang F, Alvarez-Reyes M, Pearson IV, Wolowacz S, Diwakar L. A cost-effectiveness comparison of icatibant and C1-esterase inhibitor concentrate for the symptomatic treatment of acute attacks of types I and II hereditary angioedema in the UK setting [abstract]. Value Health. 2012;15:A513.

28. Cottrell S, Tiden D, Jayaram N, Sinani R, Barnes D. Hereditary angioedema health state utility valuation study from the perspective of a representative sample of the Australian general public [abstract] Value Health. 2011;14:A324.

29. Nordenfelt P, Dawson S, Wahlgren CF, Lindfors A, Mallbris L, Bjorkander J. Quantifying the burden of disease and perceived health state in patients with hereditary angioedema in Sweden. Allergy Asthma Proc. 2014;35(2):185-190.

30. Kind P, Hardman G, Macran S. UK population norms for EQ-5D. University of York Centre for Health Economics 1999, Discussion Paper 172; 1999. Available from: https://www.york.ac.uk/media/che/ documents/papers/discussionpapers/CHEDiscussionPaper172.pdf. Accessed May 10, 2016.

31. Stafford MR, Hareendran A, Ng-Mak DS, Insinga RP, Xu R, Stull DE. EQ-5D-derived utility values for different levels of migraine severity from a UK sample of migraineurs. Health Qual Life Outcomes. 2012;10:65.

32. Westerhuis W, Zijlmans M, Fischer K, van Andel J, Leijten FS. Coping style and quality of life in patients with epilepsy: a cross-sectional study. J Neurol. 2011;258(1):37-43.

33. Terzano C, Cremonesi G, Girbino G, et al; PRISMA (PRospectIve Study on asthMA control) Study Group. 1-year prospective real life monitoring of asthma control and quality of life in Italy. Respir Res. 2012;13:112.

34. Mustur D, Vesović-Potić V, Stanisavljević D, Ille T, Ille M. Assessment of functional disability and quality of life in patients with ankylosing spondylitis. Srp Arh Celok Lek. 2009;137:524-528.

35. Dyer MT, Goldsmith KA, Sharples LS, Buxton MJ. A review of health utilities using the EQ-5D in studies of cardiovascular disease. Health Qual Life Outcomes. 2010;8:13.

36. Lee AJ, Morgan CL, Conway P, Currie CJ. Characterisation and comparison of health-related quality of life for patients with renal failure. Curr Med Res Opin. 2005;21(11):1777-1783.

37. Longworth L, Rowen D. NICE DSU Technical Support Document 10 : The use of mapping methods to estimate health state utility values; 2011 Available from: http://www.nicedsu.org.uk. Accessed May 10, 2016.

38. Ismail K, Maissi E, Thomas S, et al. A randomised controlled trial of cognitive behaviour therapy and motivational interviewing for people with type 1 diabetes mellitus with persistent sub-optimal glycaemic control: a Diabetes and Psychological Therapies (ADaPT) study. Health Technol Assess. 2010;14(22):1-101, iii-iv.

39. Marra CA, Esdaile JM, Guh D, et al. A comparison of four indirect methods of assessing utility values in rheumatoid arthritis. Med Care. 2004;42(11):1125-1131.

40. Pickard AS, Johnson JA, Feeny DH, Shuaib A, Carriere KC, Nasser AM. Agreement between patient and proxy assessments of health-related quality of life after stroke using the EQ-5D and Health Utilities Index. Stroke. 2004;35(2):607-612.
Patient Preference and Adherence

\section{Publish your work in this journal}

Patient Preference and Adherence is an international, peer-reviewed, open access journal that focuses on the growing importance of patient preference and adherence throughout the therapeutic continuum. Patient satisfaction, acceptability, quality of life, compliance, persistence and their role in developing new therapeutic modalities and compounds to optimize

\section{Dovepress}

clinical outcomes for existing disease states are major areas of interest for the journal. This journal has been accepted for indexing on PubMed Central. The manuscript management system is completely online and includes a very quick and fair peer-review system, which is all easy to use. Visit http://www. dovepress.com/testimonials.php to read real quotes from published authors. 